\title{
Virtual Reality and Serious Games Using in Distance Learning in Medicine in Bulgaria
}

\author{
https://doi.org/10.3991/ijet.v15i19.15753 \\ Galya Georgieva-Tsaneva $\left.{ }^{(}\right)$ \\ Bulgarian Academy of Sciences, Sofia, Bulgaria \\ galicanevalabv.bg \\ Ivanichka Serbezova \\ Ruse University “Angel Kanchev”, Ruse, Bulgaria
}

\begin{abstract}
The paper presents the inclusion of new innovative methods in medical education in Bulgaria. Recently, schools around the world have had to move to distance learning for their students. The use of modern technologies in the virtual classroom today is the most important part of the educational process. Effective modern devices, user-friendly platforms and appropriate educational pedagogical methods prove to be the key to excellent training. The inclusion of virtual teaching methods and serious educational games contributes to the conduct of high-level training and the formation of future medics of knowledge, skills and experience necessary for the formation of their professional qualities. The paper presents the results of a survey conducted among trainers and trainees at medical universities in Bulgaria. The analysis of the results shows the readiness of teachers and students to apply the methods of virtual learning and serious games in the educational process.
\end{abstract}

Keywords-Medical education, virtual training, serious educational games.

\section{Introduction}

The increasing use of games by the modern younger generation shows a tendency for serious educational games to become part of the educational real and online process. The use of virtual situations, video algorithms and video presentations are increasingly entering the learning process. The teacher's work in the virtual classroom is more specific than in the real classroom. The requirements for the teacher are increasing, including for example the need for the teacher to easily use the technological environment and to apply new methods adapted to the peculiarities of virtual learning. Through the virtual room, the teacher must be able to teach the learners the necessary knowledge, to assist them in the acquisition and improvement of professional habits and skills. Virtual learning should be able to solve problems such as: creating skills for learners to cope independently with tasks and building the ability to cooperate with each other, to make independent decisions and to be able to work and think in a team. Computer simulation games are suitable for use in medical, engineering and 
robotics education. They are a successful strategy $[1,2]$ for developing the skills for thinking, decision making, planning, competence enhancement, development of skills for manipulation performing. The use of video games in learning improves memory, increases attention and develops the development of cognitive functions [3]. Simulation games prove to be effective, training in medical students of an accuracy in performing manipulations. The use of virtual simulation situations is an integrative approach [4], which uses cognitive and psychomotor methods and builds valuable personal and interpersonal qualities. It is appropriate to incorporate robots in the teaching-learning process, for example in language learning, when working with students with special needs $[5,6]$ and others. Robotics in education increases students' interest [7], makes learning an attractive and integrative activity, encourages the acquisition of creative skills and is an innovative alternative for acquiring knowledge.

The improving the quality of higher education is a continuous dynamic process $[8$, 9]. Getting feedback by surveying students and teachers about the quality of educational activities is an effective way to assess the current state of the educational process.

The main purpose of this paper is to study and present the opinion of teachers and students of medicine on the inclusion of virtual methods and serious games in higher education in Bulgaria.

\section{The Methods of Effective Distance Learning}

In cases where distance learning is the only opportunity for training, the effectiveness of the methods used in this training and the technologies, platforms and electronic devices through which it is conducted is essential.

The following methods can be distinguished when conducting e-learning:

- Methods for distance learning

- Methods for monitoring the progress of the students

- Methods for evaluation of the achieved results

Pedagogical guidelines for the use of serious games in education.

The inclusion of serious games in training has a number of advantages such as [10, 11, 12]:

- Rapid increase of students' skills and knowledge

- Mastering the effective behavior of the learner in a specific situation and taking responsibility for the decisions made

- Engaging and motivating the learners

- Opportunities for effective social interaction between students and teachers

Serious game design models are based on knowledge of game design models [13] by adding pedagogical methods and tools to entertainment. The pedagogical models of the game are an important element in the cooperation between experts in computer programming, pedagogy and the specific discipline studied. Serious games can be used successfully in the formation of research and professional skills of future medi- 
cal professionals. Using serious educational games, students can virtually train their skills, to virtually repeat manipulations until they reach the required level of confidence in their abilities. Serious games are a way to present knowledge in an intriguing interactive way, oriented to support the training.

Several categories of models of serious games aimed at solving pedagogical educational tasks are proposed in $[14,15]$ :

- Integration models - game models that describe solutions that harmoniously integrate game elements and pedagogical learning objectives.

- Models of knowledge - describe solutions that trigger cognitive processes and stimulate users to process the relevant content experienced through play. They are based on the importance of cognitive feedback in educational games. They stimulate the player to reflect on their experience and tested solutions in order to further develop their mental models, to form new strategies for action.

- Presentation templates - for effective content processing. Students are challenged to extract relevant information from the games, to select pieces of information and to integrate all such elements into a coherent presentation. It is not enough for players to cope with the challenges, but they have to process the content of the game to learn.

- Social interaction and teaching models combined into models of knowledge: offering solutions that facilitate learning or teaching (trigger reflexive and metacognitive processes) through social activities and socially constructed game elements.

- Engagement models provide a way to integrate learning through play experience into a meaningful and motivating learning process. They describe solutions that motivate players to perform better in the game, facilitate learning and increase learning time through play.

A learning environment based on the integration of digital games in the teaching and learning process is presented in [16]. The presented training environment provides an opportunity to make sense of the acquired theoretical knowledge and their application in practice in the process of electronic acquisition of accounting knowledge and skills. The positive and negative features of the use of serious games in education, technological and pedagogical-methodological opportunities for combining learning with serious games are studied.

An overview of the types of serious games suitable for engineering training is presented in [17]: Scratch, Puzzle, Simulation, Video Game, Kahoot and Brain Blast. These serious games are suitable for training in the field of robotics and medicine.

In the paper [18] Lotfi offers a platform for learning out-comes analysis. The platform is based on web technologies and allows for analyzing, inferencing, visualizing data collected from mobile serious games. The presented platform is extremely interesting and useful for instructors and teachers, giving them a means to monitor the progress of their students' learning, their behavior and their ability to acquire new skills and knowledge. The platform can also be used on mobile phones, giving the opportunity to explore Mobile Serious games. Through it, users can generate their predictive models. 
In the process of teaching in higher education in Bulgaria, long-term strategies are considered and implemented, based on the incorporating of technology in education, which comply with the educational requirements and current teaching practices $[19$, 20].

\section{Results of the Study on the Virtual Learning and Serious Games in Bulgaria}

A survey on the issues of virtual education in Bulgaria was conducted in June 2019 with students learning in the specialties nurses and midwives at medical Universities in Bulgaria. Teachers' and students' views on virtual methods were surveyed using a survey created using the Google Forms application.

The survey includes 143 respondents, of which $67.10 \%$, or 96 participants are medical students in Bulgaria, the remaining $32.90 \%$ are their teachers. The online survey was conducted on a voluntary and anonymous basis. The survey was conducted among respondents from the Faculties of Public Health and Health Care of Universities in the Republic of Bulgaria, that train specialists in the professional field of Health Care, such as Ruse University "Angel Kanchev", Varna Medical University (and its branches in the country), Universities in Plovdiv, Sofia, Pleven, Stara Zagora.

Table 1 presents the advantages of virtual learning, according to the respondents in the study. The biggest advantage of virtual training according to $62.90 \%$ of the participants is the opportunity to independently choose the time and environment in which to study. More than half of the respondents accept the possibility of teaching without the need for a teacher and a student to be together at the same time and in the same place as a significant advantage of virtual learning (decentralized learning). We can consider this result as an important factor for good conduct of virtual training if necessary.

Table 1. Advantages of virtual learning

\begin{tabular}{|l|c|}
\hline \multicolumn{1}{|c|}{ Advantages of virtual learning } & Percentage of positive answers given \\
\hline $\begin{array}{l}\text { It is not necessary for a teacher and a student to be in the same } \\
\text { place and at the same time at the same time }\end{array}$ & 50.30 \\
\hline Opportunity to choose the time and environment for training & 62.90 \\
\hline $\begin{array}{l}\text { Visibility and variety of teaching methods and materials and } \\
\text { tools (video algorithms, serious games, presentations) }\end{array}$ & 38.50 \\
\hline $\begin{array}{l}\text { Achieving better efficiency of the learning process through the } \\
\text { use of video algorithms, serious games, presentations }\end{array}$ & 25.90 \\
\hline Facilitated and effective communication & 39.90 \\
\hline There are no advantages & 2.10 \\
\hline Other advantages & 0.00 \\
\hline
\end{tabular}

The use of serious games (SG) in the education of Health Care students shows a high degree of positive impact on the motivation and success of students in Health Care specialties. The games help students to build successful behavior and high selfesteem of future medics. A study of the impact of serious education games on the 
future career development of Health Care students shows that serious games can be used in the stage of their postgraduate qualification. SGs create in future nurses and midwives preliminary experience that they can rely on in their further professional growth.

Virtual learning also has its drawbacks, the assessment of which, according to the respondents, is presented in table 2 . More than half of the respondents $-67.80 \%$, believe that the lack of direct contact between student and teacher could be a disadvantage in conducting a virtual educational process. This result shows that Health Care students appreciate the need for real contact with the lecturer in mastering this extremely responsible profession, any mistake that can reflect on the patient. Of particular importance in Health Care specialties are the practical classes, which are fundamental for the development of algorithm, work discipline and confidence in the future physician. For this reason, it is essential in medical education to be able to appropriately combine traditional and innovative, virtual, methods. Such a methodology would be optimal for achieving sustainable and positive results. A significant factor in training in Bulgaria may be the lack of sufficient resources for conducting virtual training - $44.10 \%$ of respondents point to this as a challenge. This trend indicates the need to take adequate measures to allow the availability of the necessary technologies to be able to eliminate technological problems for the introduction of virtual components in training. The fact that $10.50 \%$ of the respondents' state that they do not find any disadvantages in virtual learning can be considered as positive, which shows the positive attitude towards the implementation of these innovative learning methods.

Table 2. Disadvantages of virtual learning, according to respondents

\begin{tabular}{|l|c|}
\hline \multicolumn{1}{|c|}{ Disadvantages of virtual learning } & Percentage of positive answers given \\
\hline Lack of direct contact between teacher and trainee & 67.80 \\
\hline $\begin{array}{l}\text { Problems of different nature with the resources for conducting } \\
\text { the virtual training }\end{array}$ & 44.10 \\
\hline Difficulties of teachers in working with electronic resources & 32.90 \\
\hline $\begin{array}{l}\text { Difficulties of students in working with computer and Internet } \\
\text { based resources }\end{array}$ & 11.20 \\
\hline There are no disadvantages & 10.50 \\
\hline Other disadvantages & 0.00 \\
\hline
\end{tabular}

The same trend is shown by the data from the next table 3 , which aims to visually present the attitudes of respondents to the possibility of wider representation of virtual learning for both students and teachers. $72 \%$ of respondents think that it is good for virtual learning to be more presents in their specialty. This shows that it is possible to create working groups of teachers and Health Care students to prepare and present methods and strategies for implementing virtual learning. 
Table 3. Desires for wider application of virtual learning according to the respondents

\begin{tabular}{|l|c|}
\hline \multicolumn{1}{|c|}{ Expanding the use of virtual learning } & Percentage of positive answers given \\
\hline Yes, that would definitely be helpful & 72.00 \\
\hline I can not decide & 20.30 \\
\hline I don't think that's necessary & 7.70 \\
\hline
\end{tabular}

$20.30 \%$ of respondents cannot assess whether it would be useful to advocate more virtual learning. This is an indication that it is good to provide students with a wider opportunity to learn about innovative virtual methods and the benefits of these modern teaching methods.

The remaining $7.70 \%$ of respondents do not think that there is a need for wider application of virtual learning methods. This can be seen both as a reluctance to innovate and as satisfaction with the level of implementation of virtual learning in their learning process.

\section{Conclusion}

Distance learning had to be implemented quickly in all schools in Bulgaria from March 2020. In a period of one week, teachers and students managed to get organized, to master the necessary technologies, to start working through appropriate educational platforms. The Ministry of Education of Bulgaria reports a high percentage of successful use of educational platforms in a large number of educational institutions in the country. In e-learning have successfully applied videos, serious games, video presentations, and other innovative technologies. The presented research and its results express the attitudes of teachers and Health Care students to use the methods of serious educational games and virtual learning in the bilateral process of teaching and learning. The study made the possibility to see the weaknesses in the application of these innovative teaching methods and to work on their elimination. The study shows that students and teachers in the professional field of Health Care assess virtual learning as an important factor in the process of acquiring new competencies. Future medics believe that virtual resources and serious games are important to them, especially when it comes to building clinical psychomotor skills. Serious educational games and videos are easily accessible, flexible and can be easily disseminated through the new technologies used by the younger generation.

\section{Acknowledgement}

This work was supported by the Bulgarian Ministry of Education and Science under the National Research Program "Young scientists and postdoctoral students" approved by DCM \# 577 / 17.08.2018. 


\section{References}

[1] Saravanan S., Juliet S. D. (2018). Education through Technical Games, Proc. 2018 2nd Int. Conf. Adv. Electron. Comput. Commun. ICAECC 2018, pp. 1-5, 2018. https://doi.org/10.1109/ICAECC.2018.8479425.

[2] Junior W. G., (2018). Applying design cognition in a game-based learning context to develop entrepreneurial competencies. In Proceedings of the European Conference on Games-based Learning 12th European Conference on Game Based Learning, ECGBL 2018; SKEMA Business, pp. 773-779. https://doi.org/10.34190/gbl.19.094

[3] Kefalis C. (2020). The Effects of Video Games in Memory and Attention. iJEP, 10 (1), 5161, https://doi.org/10.3991/ijep.v10i1.11290.

[4] Pavlović A., Kalezić N., Trpković S., Videnović N., Šulović L. (2018). The application of simulation in medical education - our experiences "from improvisation to simulation". Srpski arhiv za celokupno lekarstvo. May-Jun; 146(5-6):330-337. https://doi.org/10.2298/ sarh170609142p.

[5] Dimitrova, M., Wagatsuma, H., Tripathi, G.N., Ai, G. (2019). Learner attitudes towards humanoid robot tutoring systems: Measuring of cognitive and social motivation influences. In Cyber-Physical Systems for Social Applications; Dimitrova, M., Wagatsuma, H., Eds.; IGI Global: Hershey, PA, USA, 62-85. Retrieved from https://www.igi-global.com/ book/cyber-physical-systems-social-applications/210606. https://doi.org/10.4018/978-1-52 25-7879-6.ch004

[6] Zahariev, R., Valchova, N, (2019). Existing Robotics Technologies for Implementation of Special Education. In Cyber-Physical Systems for Social Applications; Dimitrova, M., Wagatsuma, H., Eds.; IGI Global: Hershey, PA, USA, 44-61. Retrieved from https://www.igi-global.com/book/cyber-physical-systems-social-applications/210606. https://doi.org/10.4018/978-1-5225-7879-6.ch003.

[7] Lizarraga C., Quiñonez Y., Aguayo R., Peraza J. (2017). Incorporation of Robots in the Teaching-Learning Process for the Different Educational Levels. 9th International Conference on Education and New Learning Technologies. Barcelona, Spain. pp. 5449-5457. https://doi.org/10.21125/edulearn.2017.2244.

[8] Pencheva V, Beloev H, Fartunova M, Kyuchukov R. (2017) New Educational Platforms in Higher Education. 56th Science Conference of Ruse University. Proceedings of University of Ruse - 2017, vol. 56, book 9, pp. 9-15. http://conf.uni-ruse.bg/bg/docs/cp17/9/9-1.pdf

[9] Beloev, Hr., V. Pencheva, R. Kyuchukov. (2018). Learning System for Experts for Internal and External Evaluation of the Quality of Higher Education, Proceedings of University of Ruse - 2018, vol. 57, book 9, pp. 30-35. http://conf.uni-ruse.bg/bg/docs/cp18/9/9-6.pdf

[10] Orloev, N., Beloev, H., Enimanev, K., Vassilev, Y., Dzhurov, K., (2011). Methodological Principles of Serious Games, Scientific Proceedings VIII International Congress "Machines, Technologies, Materials". Year XIX, Vol. 3, pp. 130-133. http://mtmcongress. com/proceedngs/2011/3/30.METHODOLOGICAL\%20PRINCIPLES\%20OF\%20SERIOU S\%20GAMES.pdf

[11] Ivanova,G., A.Smrikarov. (2006). An approach for Analysis and Evaluation of Virtual Learning Environments. in Proceedings of the e-Learning Conference'06, Computer Science Education, Coimbra, Portugal. Portugal, Coimbra, Printed in University of Ruse, pp. 1.14-1 - 1.14-6.

[12] Ivanova,G., A.Smrikarov. (2004). Some Approaches to Implementation of Virtual Learning Environments. in Proceedings of the International Conference on Computer Systems and Technologies CompSysTech'2004. Rousse, Bulgaria, Avangard Print Ltd., pp. IV.25-1 - IV.25-6. https://doi.org/10.1145/1050330.1050434

[13] Bjork, S., Holopainen J., (2005). Patterns in Game Design, Hingham: Charles River Media. https://www.worldcat.org/title/patterns-in-game-design/oclc/70774015 .

[14] Kiili, K., (2010). Call for learning-game design patterns. Educational Games: Design, Learning, and Applications. Nova Publishers. ISBN: 978-1-61209-103-7. 
[15] Ketamo, H. \& Kiili, K. (2010). Conceptual Change Takes Time: Game Based Learning Cannot be Only Supplementary Amusement. Journal of Educational Multimedia and Hypermedia, 19(4), 399-419. Waynesville, NC USA: Association for the Advancement of Computing in Education (AACE). Retrieved May 15, 2020 from https://www.learntechlib. org/p/33167.

[16] Lengyel P. S. (2020). Can the Game-Based Learning Come? Virtual Classroom in Higher Education of 21st Century. iJET, 15(2), 112 - 126, 2020. https://doi.org/10.3991/ijet.v15i $\underline{02.11521}$

[17] Talib C. A., (2019). Enhancing Students' Reasoning Skills in Engineering and Technology through Game-Based Learning, iJET, 14 (24), 69 - 80, https://doi.org/10.3991/ijet.v14i24. 12117.

[18] Lotfi, E. (2020). Towards a New Platform Based on Learning Outcomes Analysis for Mobile Serious Games, iJET, 15 (2), 42-57, https://online-journals.org/index.php/ijet/article/view/11637/6409 . https://doi.org/10.3991/ijet.v15i02.11637.

[19] Dimova, M., Paneva-Marinova, D., Pavlova, L. (2018). Towards Better Understanding of Ancient Civilizations by Storytelling and Gaming. TEM Journal, 7 (3), UIKTEN - Association for Information Communication Technology Education and Science, Serbia, ISSN:2217-8309.

[20] Paneva-Marinova, D., Rousseva, M., Dimova, M., Pavlova, L. (2018). Tell the Story of Ancient Thracians through Serious Game. Ioannides M. et al. (eds) Digital Heritage. Progress in Cultural Heritage: Documentation, Preservation, and Protection. EuroMed 2018. October 29th - November 3rd , Cyprus, 11196 LNCS, Lecture Notes in Computer Science (including subseries Lecture Notes in Artificial Intelligence and Lecture Notes in Bioinformatics), 509-517, https://doi.org/10.1007/978-3-030-01762-0_44.

\section{$7 \quad$ Authors}

Galya Georgieva-Tsaneva, Ph.D. is an Assistant Professor at the Institute of Robotics, Bulgarian Academy of Sciences, Sofia, Bulgaria. Her scientific research interests include serious educational games, web accessibility, medical information system, investigation of Heart Rate Variability of ECG data, wavelet and fractal analysis, coding and compression of information, fractal modeling, computer networks and communications, tele traffic engineering. She is the author/co-author of 3 chapters in scientific books and has published over 80 scientific articles nationally and internationally. She is a member of the Union of Informatics and Automation in Bulgaria, a member of the editorial board of international scientific journals.

Ivanichka Serbezova, Professor, Ph.D., head of the Department of Education Quality and Accreditation in Ruse University "Angel Kanchev”. Master`s Degree in Andragogy from Sofia University "St. Kliment Ohridsky" and a Bachelor's Degree in Health Care Management. In Medical University of Sofia, she acquires her major in Medical Pedagogy. Her research interests include medical education systems, optimising Healthcare Education, improving the quality of medical education. She is the author of 2 scientific books and has published over 50 scientific articles nationally and internationally. She is a member of the Union of Scientists in Bulgaria, the Bulgarian Association of Healthcare Professionals and the European Public Health Association. iserbezova@uni-ruse.bg

Article submitted 2020-05-26. Resubmitted 2020-06-20. Final acceptance 2020-06-20. Final version published as submitted by the authors. 